\title{
TGF- $\beta 1$ promotes motility and invasiveness of glioma cells through activation of ADAM17
}

\author{
YONG LU ${ }^{1,2}$, FENG JIANG ${ }^{2}$, XUGUANG ZHENG ${ }^{2}$, MARK KATAKOWSKI ${ }^{2}$, \\ BENJAMIN BULLER ${ }^{2}$, SHING-SHUN TONY TO ${ }^{1}$ and MICHAEL CHOPP ${ }^{2,3}$ \\ ${ }^{1}$ Department of Health Technology and Informatics, The Hong Kong Polytechnic University, Hong Kong SAR, P.R. China; \\ ${ }^{2}$ Department of Neurology, Henry Ford Hospital, Detroit, MI; ${ }^{3}$ Department of Physics, Oakland University, Rochester, MI, USA
}

Received December 3, 2010; Accepted December 27, 2010

DOI: $10.3892 /$ or.2011.1195

\begin{abstract}
The transforming growth factor $\beta 1$ (TGF- $\beta 1$ ) belongs to a family of structurally related polypeptide factors. TGF-beta plays an important role in the pathobiology of invasion of malignant gliomas. The objective of the present study was to investigate the impact of TNF- $\alpha$ converting enzyme (TACE/ADAM17) signaling on the process of TGF- $\beta 1$ stimulated migration and invasion of $\mathrm{T} 98 \mathrm{G}$ glioma cells. We found that TGF- $\beta 1$ increased migration and invasiveness in glioma cells. Addition of the TGF- $\beta 1$ receptor inhibitor, SB431542, reduced the TGF- $\beta 1$-stimulated migration and invasiveness of glioma cells. In addition, TGF- $\beta 1$-induced migration and invasiveness were also blocked by exposure to an ADAM17 inhibitor, TAPI-2. Furthermore, ADAM17 mRNA and protein expression were up-regulated by TGF- $\beta 1$. Treatment with SB431542 and TAPI-2 blocked TGF- $\beta 1$ induced ADAM17 protein expression. In summary, these results indicate that TGF- $\beta 1$ promotes cell migration and invasiveness of glioma cells through stimulation of ADAM17.
\end{abstract}

\section{Introduction}

Glioblastoma multiforme (GBM) is the most common primary brain tumor in adults. It represents the most malignant aggressive form of glioma, and patient survival remains at approximately 1 year despite aggressive surgery, radio- and chemotherapy. Like in all tumors, the growth of glioma cells is dysregulated, but it is the insidious invasive nature of these cells that makes complete cure impossible. During invasion, tumor cells alter the specificity and affinity of their attachment to surrounding cells and extracellular matrix proteins such as collagens, laminin and fibronectin. The regulation of adhesion molecule expression on glioma is an important step

Correspondence to: Dr Feng Jiang, Neurology Research, E\&R Building, Room 3056, Henry Ford Hospital, 2799 West Grand Boulevard, Detroit, MI 48202, USA

E-mail: fengj@neuro.hfh.edu

Key words: glioma, transforming growth factor $\beta 1$, ADAM17, migration, invasion involved in glioma invasion. The invasive nature of GBM is also regulated by the secretion of matrix modulators (1) such as the matrix metalloproteinases (MMPs) and their inhibitors, tissue inhibitors of matrix metalloproteinases (TIMPs). In GBM, gelatinase A and B (MMP-2 and MMP-9), membranetype 1 matrix metalloproteinase (MT1-MMP) and MT2-MMP as well as TIMP-1 are consistently expressed at a much higher level compared to normal brain, low-grade astrocytoma, anaplastic astrocytoma and medulloblastoma (2).

The transforming growth factor $\beta 1$ (TGF- $\beta 1$ ) belongs to a family of structurally related polypeptide factors, which restrains the growth of mammalian tissues (3). TGF- $\beta 1$ plays an important role in suppressing tumorigenic processes $(4,5)$. However, during the progression of tumors, TGF- $\beta 1$ transforms into an oncogene to stimulate growth of tumor cells (6). Recently, several studies have suggested that TGF-beta controls the motility of multi cell types (7-10). Exposure to TGF-beta caused mammary 4T1 carcinoma cells to undergo morphological changes associated with the metastatic phenotype and to invade more readily through collagen coated matrices. In addition, expression of a dominant negative truncated type II receptor has been shown to inhibit TGF-beta signaling and significantly restrict the ability of $4 \mathrm{~T} 1$ cells to establish distant metastases (7). TGF- $\beta 1$ is also a mediator in invasion and angiogenesis in malignant gliomas $(6,11,12)$. The effects of TGF- $\beta 1$ on mobility and migration are associated with changes in ECM components, including collagen, tenascin, fibronectin, laminin, vitronectin, MMP2 and MMP9 (6,13-16). The changes mediated by TGF- $\beta 1$ in the ECM and the cytoskeleton might influence cell shape and mobility, which may be connected with Ras/PI3K signaling and the TGF- $\beta 1$-induced activation of Smad and RhoA signaling (17). Clinical and experimental data have shown that TGF-beta is elevated in GBM cell lines and specimens (18-20). Because TGF-beta is frequently and highly expressed in brain tumors, especially in gliomas $(13,21,22)$, it can be used as a molecular target of brain tumor therapy, and the use of specific antisense oligonucleotides against TGF- $\beta 1$ could inhibit glioma invasion $(18,23)$.

ADAMs are best known as ectodomain sheddases, and their domains function as metalloproteases. The ADAM family belongs to one of the $\mathrm{Zn}$-dependent metalloproteinases $(24,25)$. TNF- $\alpha$ converting enzyme (TACE/ADAM17) is the primary secretase responsible for releasing the soluble 
form of TNF- $\alpha$ from the plasma membrane (26). Besides the release of TNF- $\alpha$, ADAM17 also contributes to the development of disease through processing numerous growth factors and growth factor receptors. ADAM17 is an important member of the ADAM family and is involved in proteolysis of collagen IV of ECM and also the release from the cell surface of several integrins, suggesting that ADAM17 affects the invasive activity of different cells including glioma cells (27). ADAM17 is a primary upstream component of multiple EGFR pro-ligands $(28,29)$. EGFR binding with ligands subsequently activates MEK/ERK and PI3K/Akt pathways, which contribute to invasiveness and other malignant phenotypes (30). Recently, TGF- $\beta 1$ was shown to rapidly induce phosphorylation of TACE/ADAM17 (31-33). However, there is no report on the relationship between TGF- $\beta 1$ and ADAM17 in glioma.

In the present study, we investigated whether ADAM17 affects the process of TGF- $\beta 1$-stimulated T98G glioma cell migration and invasion. Our results demonstrate that TGF- $\beta 1$ increases migration and invasiveness in glioma cells. TGF- $\beta 1$ receptor inhibitor, SB431542, decreases the TGF- $\beta 1$-stimulated migration and invasiveness of glioma cells. Furthermore, the TGF- $\beta 1$-induced migration and invasiveness were also blocked by exposure to the ADAM17 inhibitor TAPI-2.

\section{Materials and methods}

Cell culture. Human glioblastoma T98G was obtained from American Type Culture Collection (ATCC, Rockville, MD). It was maintained in DMEM containing $10 \%$ fetal bovine serum (FBS), 100 units/ml penicillin, $50 \mu \mathrm{g} / \mathrm{ml}$ streptomycin, and $100 \mu \mathrm{g} / \mathrm{ml}$ amphotericin (Life Technologies, Gaithersburg, MD, USA). Cell cultures were maintained in $75-\mathrm{cm}^{2}$ flasks and kept in a humidified atmosphere with $5 \% \mathrm{CO}_{2}$ at $37^{\circ} \mathrm{C}$.

MTT (3-(4,5-dimethyl-thiagol-2yl)-2,5 diplenyltetrazollium) assay. To measure cell viability, cells were seeded into 96-well plates at a density of $1 \times 10^{4}$ per well. After overnight incubation, the culture medium was removed and cells were rinsed with phosphate-buffered saline (PBS) and incubated with different concentrations of TGF- $\beta 1$ (Invitrogen, Carlsbad, CA, USA) in complete medium. After $24 \mathrm{~h}$ of treatment, MTT was added to each well and incubated for an additional $4 \mathrm{~h}$ to allow mitochondrial dehydrogenase to convert MTT into insoluble formazan crystals. The medium was then aspirated, and formazan was solubilized by adding $150 \mu \mathrm{l}$ of DMSO. The absorption of solubilized formazan was measured at the wavelength of $490 \mathrm{~nm}$ by an ELISA plate reader (EL340 microplate reader; Bio-Tek Instruments, Winooske, VT).

Wound scratch assay. Cells were seeded at a density of $5 \times 10^{5}$ per well in 6-well plates in complete medium. After 24-h incubation, the monolayers were scratched with a 1-ml plastic pipette tip to create a uniform wound. The wound area was then examined after 12 and $24 \mathrm{~h}$ of incubation under an optical phase-contrast microscope at x 5 magnification. Photographs of five random fields were taken and the cell migration ability was expressed by the percentage of total area covered by cells.
Invasion assay. BD BioCoat matrigel invasion chambers (8.0 $\mu \mathrm{m}$ pore size with polycarbonate membrane; BD Biosciences, Cowley, UK) were used to examine the ability of $\mathrm{T} 98 \mathrm{G}$ cells to penetrate the extracellular matrix (ECM). Cells $\left(5 \times 10^{4}\right)$ were suspended in $500 \mu \mathrm{l}$ of serum-free medium and added to the upper chamber while the lower chamber was filled with $0.75 \mathrm{ml}$ of complete medium containing FBS, which served as a chemo-attractant. Cells were then incubated for $24 \mathrm{~h}$ at $37^{\circ} \mathrm{C}$. After removal of cells on the upper surface of the membrane, cells on the lower surface of the membrane were stained with CellTracker ${ }^{\mathrm{TM}}$ Green (Molecular Probes, Eugene, OR) for $45 \mathrm{~min}$ and fixed in $4 \%$ formaldehyde. Nine fields of cells were counted randomly in each well under a fluorescent microscope at $\times 200$ magnification. Data are expressed as the percentage of invasive cells as compared with the control. All the experiments were performed in duplicates and results were expressed as the mean \pm SEM of 3 independent experiments.

Gelatin zymography assay. T98G glioma cells were grown in $60 \mathrm{~mm}$ dishes at a density of $5 \times 10^{5}$ cells per dish overnight. After removal of the complete medium, the cells were further incubated with serum-free medium containing TGF- $\beta 1$ and inhibitors for $24 \mathrm{~h}$. Culture supernatants were collected and concentrated with Amicon Ultra-4 Centrifugal Filter Units (Amicon, Billerica, MA, USA). Total supernatant protein concentration was determined by the BCA method. Cellular protein $(1 \mu \mathrm{g})$ was used for analysis by gel substrate zymography. Samples were applied without reduction on $10 \%$ polyacrylamide gel containing $0.1 \%$ gelatin. The gels were washed for $1 \mathrm{~h}$ in $2.5 \%$ Triton X-100 and incubated in substrate buffer $\left(25 \mathrm{mM}\right.$ Tris- $\mathrm{HCl}, 0.9 \% \mathrm{NaCl}, 5 \mathrm{mM} \mathrm{CaCl}{ }_{2}$, and $0.05 \% \mathrm{Na}_{3} \mathrm{~N}, \mathrm{pH} 7.5$ ) at $37^{\circ} \mathrm{C}$ overnight. Gels were stained with Coomassie blue R-250 for $1 \mathrm{~h}$ and destained accordingly. MMP activity appeared as transparent bands on a blue background. The clear bands of proteolytic zones corresponding to MMP-2 and MMP-9 were determined by densitometry. The experiment was repeated three times. Human MMP-2 and MMP-9 gelatinase zymography standards (Chemicon, Temecula, CA, USA) were used as markers.

Western blot analysis. T98G cells ( $5 \times 10^{5}$ cells) were seeded onto the $60-\mathrm{mm}$ dishes. After treatment with indicated concentrations for $24 \mathrm{~h}$, cells were harvested and rinsed with PBS followed by extraction in $200 \mu$ l RIPA lysis buffer $(50 \mathrm{mM}$ Tris $\mathrm{HCl}, 150 \mathrm{mM} \mathrm{NaCl}, 1 \% \mathrm{NP}-40,0.5 \%$ sodium deoxycholate, $1 \mathrm{mM}$ EDTA, $0.1 \%$ SDS and $0.01 \%$ sodium azide, $\mathrm{pH}$ 7.4). Equal amounts of proteins, as determined by the BCA protocol (Pierce, Rockford, IL), were run on $10 \%$ Tris-Glycine gels (Invitrogen) and then transferred to PVDF membranes (Whatman). The membranes were blocked with $0.1 \%$ I-Block (Applied Biosystems, Foster, CA) in PBS-T (0.1\% Tween-20) at room temperature for $1 \mathrm{~h}$, followed by incubation with primary antibodies against ADAM17 (Abcam, Cambridge, MA) and actin (Santa Cruz Biotechnology, Santa Cruz, CA) at $4^{\circ} \mathrm{C}$ overnight. The membranes were washed with PBS-T (0.1\% Tween-20) and incubated for $1 \mathrm{~h}$ at room temperature with horseradish peroxidase-conjugated secondary antibodies (Bio-Rad Laboratories, Hercules, CA). Following washing, the specific proteins were detected using a SuperSignal West 
Table I. Information on the primers used for real-time polymerase chain reaction.

\begin{tabular}{lcc}
\hline Gene & Genbank accession no. & \multicolumn{1}{c}{ Sequence } \\
\hline ADAM17 & NM020306 & 5'-ACT CTG AGG ACA GTT AAC CAA ACC-3' \\
& & 5'-AGT AAA AGG AGC CAA TAC CAC AAG-3' \\
$T B P$ & NM003194 & 5'-TGC ACA GGA GCC AAG AGT GAA-3' \\
& & 5'-CAC ATC ACA GCT CCC CAC CA-3' \\
\hline
\end{tabular}

ADAM, a disintegrin and metalloproteinase; TBP, TATA-binding protein.

Pico chemiluminescent protein detection kit (Pierce). Each experiment was repeated three times.

Real-time RT-PCR. Quantitative RT-PCR was carried out using real-time PCR with the SYBR-Green reporter. After treatment, T98G cells were washed with PBS and RNA was isolated by employment of the RNeasy Mini Kit (Qiagen, Valencia, CA, USA). OD $260 \mathrm{~nm}$ was used to determine RNA yield. RNA was subsequently reverse transcribed to cDNA with the SuperScript First-strand Synthesis System (Invitrogen). Quantitative RT-PCR was carried out afterward. Primer (Invitrogen) concentrations $(10 \mathrm{nM})$ were optimized before use. SYBR-Green PCR master kit was used with the appropriate concentrations $(10 \mathrm{nM})$ of forward and reverse primers in a total volume of $20 \mu \mathrm{l}$. PCR reactions contained $1 \mu \mathrm{l}$ cDNA. Optimization was carried out for each gene-specific primer prior to the experiment to confirm that $10 \mathrm{nmol} / 1$ primer concentrations did not produce non-specific primer-dimer amplification signals in no-template control wells. Quantitative RT-PCR was carried out using an ABI 7000 PCR instrument (PE Applied Biosystems) with the three-stage program parameters provided by the manufacturer, as follows: $2 \mathrm{~min}$ at $50^{\circ} \mathrm{C}, 10 \mathrm{~min}$ at $95^{\circ} \mathrm{C}$, and then 40 cycles of $15 \mathrm{sec}$ at $95^{\circ} \mathrm{C}$ and $1 \mathrm{~min}$ at $60^{\circ} \mathrm{C}$. Specificity of the produced amplification product was confirmed by examination of dissociation reaction plots. A distinct single peak indicated that a single DNA sequence was amplified during RT-PCR. Each sample was tested in triplicate with quantitative RT-PCR, and samples obtained from three independent experiments were used for analysis of relative gene expression. The following primers for real-time PCR were designed using Primer Premier 5 software (Palo Alto, CA, USA) (Table I). TATA-binding protein was used as the internal control.

Statistical analysis. Data were presented as the mean and standard error. Statistical significance was analyzed by one-way ANOVA using the GraphPad Prism software (version 4.0). A P-value $<0.05$ was considered significant.

\section{Results}

TGF- $\beta 1$ stimulates glioblastoma cell migration and invasion. We examined the effects of TGF- $\beta 1$ on the motility and invasive ability of T98G cells in a scratch-closure assay and matrigel invasion assay. T98G cells then were treated with
TGF- $\beta 1$ from 0.1 to $2.0 \mathrm{ng} / \mathrm{ml}$ for different time, and their ability to cover the wound area was assessed. There was no significant increase on the percentage of total area that was covered by the cells exposed to TGF- $\beta 1$ for $12 \mathrm{~h}$ as compared with the control groups (Fig. 1B). The motility of the TGF- $\beta 1$ treated cells was significantly increased and 1.4-fold over untreated cells after $24 \mathrm{~h}$. Before evaluating the motility and invasiveness, T98G glioma cells were treated with different concentrations $(0.1,1$, and $10 \mathrm{ng} / \mathrm{ml})$ of TGF- $\beta 1$ for $24 \mathrm{~h}$ and cell viability were determined by MTT assay. TGF- $\beta 1$ had no significant effect on cell viability from 0.1 to $10 \mathrm{ng} / \mathrm{ml}$ and for the length of time (Fig. 1A). This indicates that cell viability did not affect T98G cell motility. To confirm the contribution of TGF- $\beta 1$ to the motility of glioma cells, the cells were treated with a selective inhibitor of TGF- $\beta 1$ signaling pathway, SB431542 which reversed the stimulatory effect of TGF- $\beta 1$ on cell migration (Fig. $1 C$ and D). Taken together, the results demonstrate that TGF- $\beta 1$ promotes the motility of glioma cells.

The effect of TGF- $\beta 1$ on the invasion of glioma cells was measured with a Matrigel invasion assay. The ability of glioma cells to invade Matrigel was significantly increased by exposure to TGF- $\beta 1$, as shown in the wound-scratch assay (Fig. 1E and F). Conversely, the TGF- $\beta 1$-induced T98G glioma cell invasiveness was significantly decreased by SB431542. These results indicate that TGF- $\beta 1$ contributes to glioma cells invasion.

ADAM17 signaling mediates TGF- $\beta 1$-induced migration and invasion of glioma cells. Numerous studies have shown that ADAM17 affects the invasive activity of different cells including glioma cells. TGF- $\beta 1$ rapidly induces phosphorylation of ADAM17 (31-33). Our above results suggest that TGF- $\beta 1$ plays a critical role in the motility and invasiveness of glioma cells, and thus ADAM17 may have an effect on TGF- $\beta 1$-induced cell migration and invasion. To determine if ADAM17 mediates the TGF- $\beta 1$-induced cell motility and invasion, T98G glioma cells were treated with TGF- $\beta 1$ in the presence or absence of the ADAM17 activity inhibitor-TAPI-2 for $24 \mathrm{~h}$, and motility and invasiveness were then assessed. Our results showed that the addition of TAPI-2 attenuated the stimulatory effect of TGF- $\beta 1$ on cell migration (Fig. $2 \mathrm{~A}$ and $\mathrm{B}$ ) and invasiveness (Fig. 2C and D), which indicated that ADAM17 may play a role in TGF- $\beta 1$-induced glioma cell migration and invasion. 
A

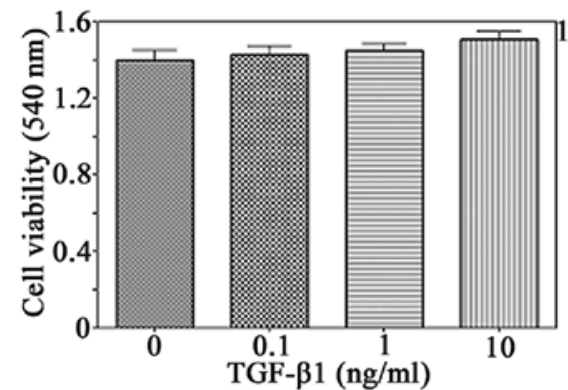

C
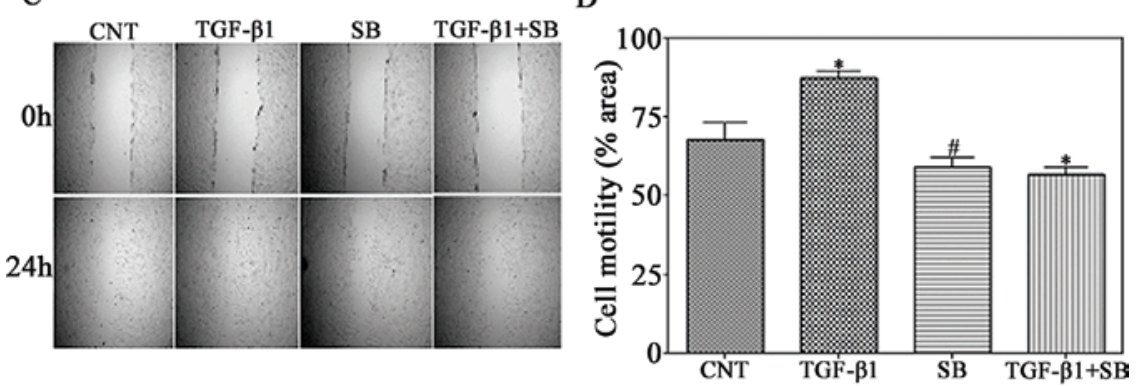

$\mathrm{E}$

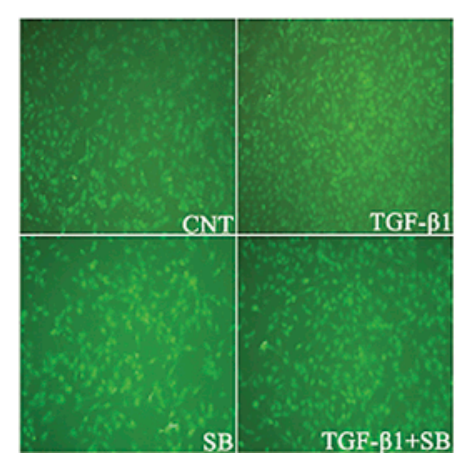

B

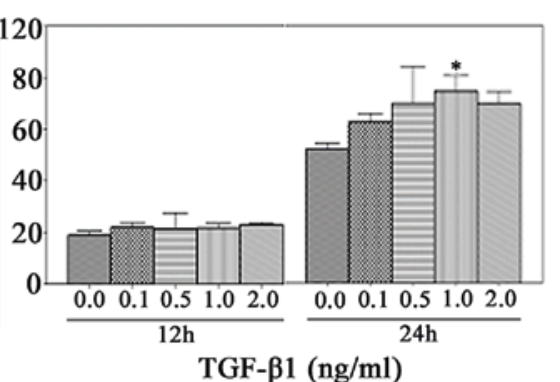

D
F

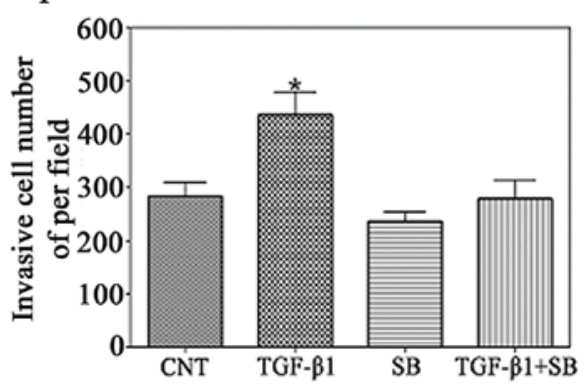

Figure 1. TGF- $\beta 1$ promotes glioblastoma cells migration and invasion. (A) T98G cells were treated with the various doses of human recombinant TGF- $\beta 1$ (Invitrogen). Cell viability was measured after treatment for $24 \mathrm{~h}$ by MTT assay. (B and C) Confluent T98G glioblastoma cell monoplayers were scratched with a pipette tip and then treated with TGF- $\beta 1(1 \mathrm{ng} / \mathrm{ml})$ in the presence or absence of SB (Sigma-Aldrich, St. Louis, MO) $(10 \mathrm{nmol} / \mathrm{ml})$ for $24 \mathrm{~h}$. Cell migration to the wound area was then examined by light microscope for $24 \mathrm{~h}$ post-scratch. (D) The percentage of total area covered by cells was assessed with MCID software. ${ }^{*} \mathrm{P}<0.05$ and ${ }^{*} \mathrm{P}<0.01$, compared with control group. (E) T98G glioma cells were seeded onto the upper BD BioCoat matrigel invasion chamber in serum-free medium containing TGF- $\beta 1(1 \mathrm{ng} / \mathrm{ml})$ in the presence or absence of SB $(10 \mathrm{nmol} / \mathrm{ml})$. After $24 \mathrm{~h}$ of incubation, cells on the lower surface of the membrane were stained with CellTracker ${ }^{\mathrm{TM}}$ Green (Molecular Probes, Eugene, OR), and (F) 9 different areas of invaded cells were counted by a fluorescent microscope. ${ }^{*} \mathrm{P}<0.01$, compared with control group.

TGF- $\beta 1, S B$ (TGF- $\beta 1$ receptor I) inhibitor and TAPI-2 (ADAM17 activity inhibitor) does not change the MMP-2 activity. To evaluate if TGF- $\beta 1$-induced cell migration and invasion resulted from elevated levels of MMPs, supernatant from T98G cells exposed to TGF- $\beta 1$, SB431542, and TAPI-2 for $24 \mathrm{~h}$ were collected and analyzed by gelatin zymography. From Fig. 3, the results showed that TGF- $\beta 1$ in the absence or presence of SB and TAPI-2 did not significantly change the MMP-2 activity. However, there is no detectable MMP-9 activity in cell supernatants. These data indicated that MMP-2 activity is not involved in the increase of TGF- $\beta 1$-induced T98G glioma invasion.

TGF- $\beta 1$ induces ADAM17 mRNA expression in glioblastoma cells. To determine if TGF- $\beta 1$ changes ADAM17 gene expression, the levels of ADAM17 mRNA were measured by real-time RT-PCR. The mRNA expression of ADAM17 in T98G was up-regulated by treatment of TGF- $\beta 1$ at $1 \mathrm{ng} / \mathrm{ml}$, and increased 2.6-times as compared to the starting points (Fig. 4A).

TGF- $\beta 1$ promotes motility and invasiveness of glioma cells possibly via stimulation of ADAM17. To clarify the possible molecular mechanisms underlying the TGF- $\beta 1$ stimulated ADAM17 expression in cell motility and invasion of T98G glioma cells, measurements of protein expression of ADAM17 were performed by Western blot analysis. As shown in the Fig. 4B, the expression of ADAM17 was significantly increased after treatment with TGF- $\beta 1$ at $1 \mathrm{ng} / \mathrm{ml}$. Blockage of the TGF- $\beta 1$ signaling pathway by TGF- $\beta 1$ receptor I inhibitor, SB431542, significantly decreased the TGF- $\beta 1$ stimulated ADAM17 expression. Similarly, after exposure to the ADAM17 inhibitor, TAPI-2, a reduced expression of TGF- $\beta 1$-mediated ADAM17 was also observed. These data suggest that ADAM17 plays a critical role in the TGF- $\beta 1$ 
A

B
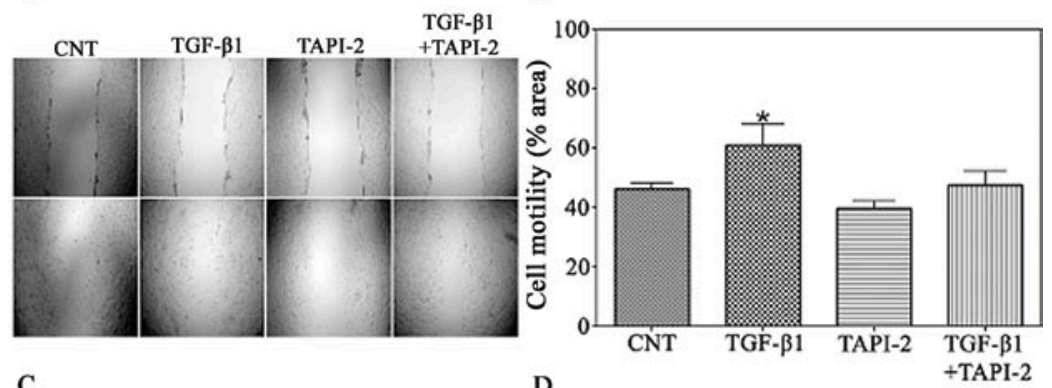

$\mathrm{C}$
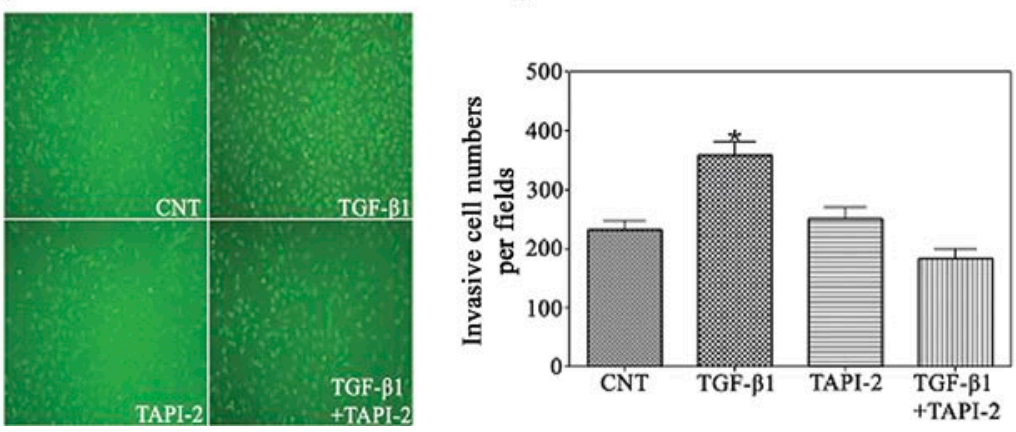

Figure 2. TAPI-2, as an ADAM17 activity inhibitor, inhibits TGF- $\beta 1$-induced glioma cell migration and invasion. (A) Confluent T98G glioblastoma cell monoplayers were scratched with a pipette tip and then treated with TGF- $\beta 1(1 \mathrm{ng} / \mathrm{ml})$ in the presence or absence of TAPI-2 (Peptides International, Louisville, KY, USA) $(100 \mathrm{nmol} / \mathrm{ml})$ for $24 \mathrm{~h}$. Cell migration to the wound area was then examined by light microscope for 24-h post-scratch. (B) The percentage of total area covered by cells was assessed with MCID software. " $\mathrm{P}<0.01$, compared with control group. (C) T98G glioma cells were seeded onto the upper BD BioCoat matrigel invasion chamber in serum-free medium containing TGF- $\beta 1(1 \mathrm{ng} / \mathrm{ml})$ in the presence or absence of TAPI-2 $(100 \mathrm{nmol} / \mathrm{ml})$. After $24 \mathrm{~h}$ of incubation, cells on the lower surface of the membrane were stained with CellTracker ${ }^{\mathrm{TM}}$ Green (Molecular Probes), and (D) 9 different areas of invaded cells were counted by a fluorescent microscope. ${ }^{*} \mathrm{P}<0.01$, compared with control group.

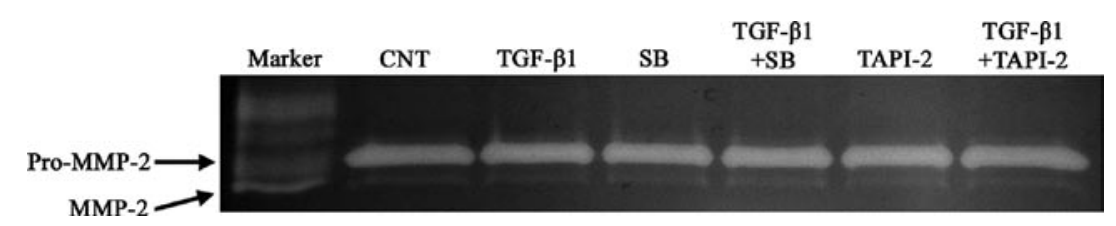

Figure 3. Effect of TGF- $\beta 1$, SB, and TAPI-2 on the MMP-2 activity of supernatant of T98G. Supernatant from T98G cells treated with TGF- $\beta 1$, SB, and TAPI-2 under the condition of serum-free medium for $24 \mathrm{~h}$ were collected and subjected to gelatin zymography. A human MMP-2 and MMP-9 standard was used as a positive control.
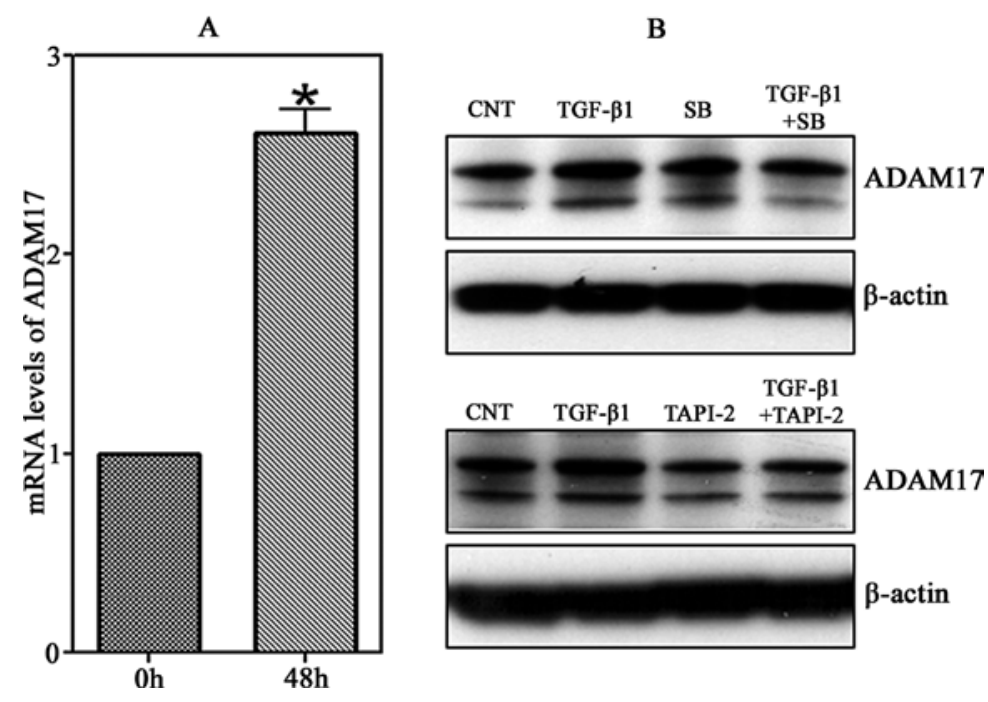

Figure 4. TGF- $\beta 1$ promotes the expression of ADAM17 in T98G. (A) T98G glioma cells were plated in 6-well plates, and then treated with TGF- $\beta 1$ (1 ng/ml) for the times showed. The mRNA levels of ADAM17 in T98G glioblastoma cells were up-regulated by TGF- $\beta 1$. The levels of ADAM17 mRNA were determined by real-time RT-PCR. "P<0.01 compared with $0 \mathrm{~h}$. (B) T98G glioma cells were incubated with TGF- $\beta 1(1 \mathrm{ng} / \mathrm{ml})$ in the presence or absence of SB (10 nmol/ml) or TAPI-2 $(100 \mathrm{nmol} / \mathrm{ml})$, and the total protein was harvested for Western blot analysis with antibodies against ADAM17 and $\beta$-actin. 
increases of migration and invasion, and TGF- $\beta 1$ stimulates ADAM17 expression through a TGF- $\beta 1$ receptor.

\section{Discussion}

In the present study, we used $\mathrm{T} 98 \mathrm{G}$ glioma cell lines to investigate the effect of TGF- $\beta 1$ on the migration and invasive ability of brain tumor cells as well as the effect of TGF- $\beta$ receptor I inhibitor and ADAM17 inhibitor on these processes.

Our data showed that TGF- $\beta 1$ significantly stimulates T98G cell migration and invasion, which is consistent with data from a recent study of the effect of microglia-derived TGF- $\beta 1$ on glioma invasion (34). For the duration of the experiment, TGF- $\beta 1$ had no effect on the overall cell viability of T98G glioma, which indicates that the difference in motility and invasiveness is not because of effect on cell survival. Furthermore, we found that TGF- $\beta 1$-induced migration and invasion were significantly reduced by SB431542, a TGF- $\beta$ receptor I inhibitor. These data suggest that abnormal activation of this pathway may contribute to invasion in a variety of cancers, including gliomas, and inhibition of the TGF- $\beta 1$ pathway may be useful for reducing glioma invasion. However, the mechanisms by which TGF-beta signaling enhances cellular motility and invasiveness warrant further investigation.

ADAM17 is also involved in proteolytical digestion of collagen IV of the ECM and the release from the cell surface of several integral proteins, which suggest that ADAM17 affects the invasive activity of a variety of cancers, including glioma cells (27). Several recent studies reported that TGF- $\beta 1$ induces a rapid activation of TACE/ADAM17 (31-33). In the present study, ADAM17 mRNA expression in T98G cells was significantly increased compared to the starting time point by real-time RT-PCR. Protein level of ADAM17 was highly expressed under incubation with TGF- $\beta 1$. The increase of mRNA corresponded with protein expression of ADAM17.

We have found that TGF- $\beta$ signaling plays a role in the migration and invasiveness of glioma cells. We then examined if ADAM17 contributes to the invasive potential of glioma induced by TGF- $\beta 1$. With employment of Matrigel invasion assay and wound-scratch assay, we observed that blockage of ADAM17 with the ADAM17 inhibitor TAPI-2 diminished TGF- $\beta 1$ induced migration and invasion. Consistent with these findings, analysis of Western blotting revealed that additional treatment with SB431542 resulted in a significant decrease in the protein expression of ADAM17 and attenuated TGF- $\beta 1$-induced increase of ADAM17. Exposure to TAPI-2 did not change the ADAM17 protein expression. But addition of TAPI- 2 decreased the stimulation effect of TGF- $\beta 1$ on ADAM17. Taken together, these findings suggest that ADAM17 mediates TGF- $\beta 1$ induced migration and invasion and may be a target for anti-invasive therapy of brain tumors.

MMPs promote tumor cell invasion (1). As ADAM17 is a member of the metalloproteinase superfamily, TAPI-2 may inhibit MMPs in addition to ADAM17. To determine the role of ADAM17 in the invasion of brain tumor cells, we therefore examined the effects of TAPI- 2 on the activities of MMP-2 and MMP-9 involved in proteolysis of the ECM. The data showed that TAPI-2 does not change MMP-2 activity in the presence or absence of TGF- $\beta 1$, which is consistent with our recent study of T98G glioma cells and 9L gliosarcoma cells (29). In addition, there was no detectable MMP-9 activity in cell supernatants. However, TAPI-2 caused a significant decrease of T98G cell invasion stimulated by TGF- $\beta 1$. The expression level of ADAM17 corresponded with the invasive potential of glioma cells, indicating that, independently of MMP2, ADAM17 mediates tumor invasion induced by TGF- $\beta 1$.

ADAM17 is a primary upstream component for multiple EGFR pro-ligands $(28,29)$. EGFR binding with ligands subsequently activates MEK/ERK and PI3K/Akt pathways, which contribute to invasiveness and other malignant phenotypes (30). Our previous study has reported that ADAM17 contributes to invasion through the EGFR/PI3K/Akt pathway in glioma (29). Taken together, the present results suggest that promotion of motility and invasion of glioma cells by TGF- $\beta 1$ may be through activation of ADAM17/EGFR/PI3K/Akt signaling pathway.

In summary, our data demonstrate that TGF- $\beta 1$ could stimulate T98G glioma cell migration and invasiveness. Inhibition of ADAM17 contributes to the decrease of invasiveness stimulated by TGF- $\beta 1$. This study provides insight into the mechanism by which TGF- $\beta 1$ activates the invasive behavior of glioma cells, which can be useful in identifying therapeutic targets to inhibit TGF- $\beta 1$-dependent glioma migration and invasion.

\section{Acknowledgments}

We gratefully acknowledge James Jiang for editorial support and assistance in the writing of the report. This study was supported by NIH grant RO1 CA129446.

\section{References}

1. Lampert K, Machein U, Machein MR, Conca W, Peter HH and Volk B: Expression of matrix metalloproteinases and their tissue inhibitors in human brain tumors. Am J Pathol 153: 429-437, 1998.

2. Nakano A, Tani E, Miyazaki K, Yamamoto Y and Furuyama J: Matrix metalloproteinases and tissue inhibitors of metalloproteinases in human gliomas. J Neurosurg 83: 298-307, 1995.

3. Siegel PM and Massague J: Cytostatic and apoptotic actions of TGF-beta in homeostasis and cancer. Nat Rev Cancer 3: 807-821, 2003.

4. Akhurst RJ and Derynck R: TGF-beta signaling in cancer - a double-edged sword. Trends Cell Biol 11: S44-S51, 2001.

5. Derynck R, Akhurst RJ and Balmain A: TGF-beta signaling in tumor suppression and cancer progression. Nat Genet 29: $117-129,2001$.

6. Hau P, Kunz-Schughart LA, Rummele $\mathrm{P}$, et al: Tenascin-C protein is induced by transforming growth factor-betal but does not correlate with time to tumor progression in high-grade gliomas. J Neurooncol 77: 1-7, 2006.

7. McEarchern JA, Kobie JJ, Mack V, et al: Invasion and metastasis of a mammary tumor involves TGF-beta signaling. Int J Cancer 91: 76-82, 2001.

8. Fu H, Hu Z, Wen J, Wang K and Liu Y: TGF-beta promotes invasion and metastasis of gastric cancer cells by increasing fascin1 expression via ERK and JNK signal pathways. Acta Biochim Biophys Sin (Shanghai) 41: 648-656, 2009.

9. Muraoka-Cook RS, Shin I, Yi JY, et al: Activated type I TGFbeta receptor kinase enhances the survival of mammary epithelial cells and accelerates tumor progression. Oncogene 25: 3408-3423, 2006.

10. Leivonen SK and Kahari VM: Transforming growth factor-beta signaling in cancer invasion and metastasis. Int $\mathbf{J}$ Cancer 121: 2119-2124, 2007. 
11. Platten M, Wick W, Wild-Bode C, Aulwurm S, Dichgans J and Weller M: Transforming growth factors beta(1) (TGFbeta(1)) and TGF-beta(2) promote glioma cell migration via up-regulation of alpha(V)beta(3) integrin expression. Biochem Biophys Res Commun 268: 607-611, 2000.

12. Stiles JD, Ostrow PT, Balos LL, et al: Correlation of endothelin-1 and transforming growth factor beta 1 with malignancy and vascularity in human gliomas. J Neuropathol Exp Neurol 56 : 435-439, 1997.

13. Platten M, Wick W and Weller M: Malignant glioma biology: role for TGF-beta in growth, motility, angiogenesis, and immune escape. Microsc Res Tech 52: 401-410, 2001.

14. Platten M, Wild-Bode C, Wick W, Leitlein J, Dichgans J and Weller M: N-[3,4-dimethoxycinnamoyl]-anthranilic acid (tranilast) inhibits transforming growth factor-beta relesase and reduces migration and invasiveness of human malignant glioma cells. Int J Cancer 93: 53-61, 2001.

15. Arslan F, Bosserhoff AK, Nickl-Jockschat T, Doerfelt A, Bogdahn U and Hau P: The role of versican isoforms V0/V1 in glioma migration mediated by transforming growth factor-beta2. Br J Cancer 96: 1560-1568, 2007.

16. Miyake K, Kimura S, Nakanishi M, et al: Transforming growth factor-betal stimulates contraction of human glioblastoma cell-mediated collagen lattice through enhanced alpha2 integrin expression. J Neuropathol Exp Neurol 59: 18-28, 2000.

17. Bhowmick NA, Ghiassi M, Bakin A, et al: Transforming growth factor-beta1 mediates epithelial to mesenchymal transdifferentiation through a RhoA-dependent mechanism. Mol Biol Cell 12: 27-36, 2001.

18. Jachimczak P, Hessdorfer B, Fabel-Schulte K, et al: Transforming growth factor-beta-mediated autocrine growth regulation of gliomas as detected with phosphorothioate antisense oligonucleotides. Int J Cancer 65: 332-337, 1996.

19. Horst HA, Scheithauer BW, Kelly PJ and Kovach JS: Distribution of transforming growth factor-beta 1 in human astrocytomas. Hum Pathol 23: 1284-1288, 1992.

20. Schneider T, Sailer M, Ansorge S, Firsching R and Reinhold D: Increased concentrations of transforming growth factor betal and beta2 in the plasma of patients with glioblastoma. J Neurooncol 79: 61-65, 2006

21. Samuels V, Barrett JM, Bockman S, Pantazis CG and Allen MB Jr: Immunocytochemical study of transforming growth factor expression in benign and malignant gliomas. Am J Pathol 134: 894-902, 1989.

22. Kjellman C, Olofsson SP, Hansson O, et al: Expression of TGF-beta isoforms, TGF-beta receptors, and SMAD molecules at different stages of human glioma. Int J Cancer 89: 251-258, 2000
23. Paulus W, Baur I, Huettner C, et al: Effects of transforming growth factor-beta 1 on collagen synthesis, integrin expression, adhesion and invasion of glioma cells. J Neuropathol Exp Neurol 54: 236-244, 1995

24. Lu X, Lu D, Scully M and Kakkar V: ADAM proteins-therapeutic potential in cancer. Curr Cancer Drug Targets 8: 720-732, 2008.

25. Kheradmand F and Werb Z: Shedding light on sheddases: role in growth and development. Bioessays 24: 8-12, 2002.

26. Kenny PA: TACE: a new target in epidermal growth factor receptor dependent tumors. Differentiation 75: 800-808, 2007.

27. Wildeboer D, Naus S, Amy Sang QX, Bartsch JW and Pagenstecher A: Metalloproteinase disintegrins ADAM8 and ADAM19 are highly regulated in human primary brain tumors and their expression levels and activities are associated with invasiveness. J Neuropathol Exp Neurol 65: 516-527, 2006.

28. Zheng X, Jiang F, Katakowski M, et al: Sensitization of cerebral tissue in nude mice with photodynamic therapy induces ADAM17/TACE and promotes glioma cell invasion. Cancer Lett 265: 177-187, 2008.

29. Zheng X, Jiang F, Katakowski M, et al: Inhibition of ADAM17 reduces hypoxia-induced brain tumor cell invasiveness. Cancer Sci 98: 674-684, 2007.

30. Tsatas D, Kanagasundaram V, Kaye A and Novak U: EGF receptor modifies cellular responses to hyaluronan in glioblastoma cell lines. J Clin Neurosci 9: 282-288, 2002.

31. Wang SE, Xiang B, Guix M, et al: Transforming growth factor beta engages TACE and ErbB3 to activate phosphatidylinositol-3 kinase/Akt in ErbB2-overexpressing breast cancer and desensitizes cells to trastuzumab. Mol Cell Biol 28: 5605-5620, 2008.

32. Wang SE, Xiang B, Zent R, Quaranta V, Pozzi A and Arteaga CL: Transforming growth factor beta induces clustering of HER 2 and integrins by activating Src-focal adhesion kinase and receptor association to the cytoskeleton. Cancer Res 69: 475-482, 2009.

33. Murillo MM, del Castillo G, Sanchez A, Fernandez M and Fabregat I: Involvement of EGF receptor and c-Src in the survival signals induced by TGF-betal in hepatocytes. Oncogene 24: 4580-4587, 2005.

34. Wesolowska A, Kwiatkowska A, Slomnicki L, et al: Microgliaderived TGF-beta as an important regulator of glioblastoma invasion-an inhibition of TGF-beta-dependent effects by shRNA against human TGF-beta type II receptor. Oncogene 27: 918-930, 2008. 